\title{
Longitudinal effects of poverty on men's perpetration of partner violence in South Africa
}

\author{
Hatcher, AM, ${ }^{1,2}$ Neilands, T, ${ }^{3}$ Rebombo, D, ${ }^{4}$ Weiser, SD, ${ }^{3}$ Christofides, $\mathrm{NJ}^{2}$
}

${ }^{1}$ University of North Carolina, Chapel Hill, NC, USA

${ }^{2}$ University of the Witwatersrand, Johannesburg, South Africa

${ }^{3}$ University of California, San Francisco, CA, USA

${ }^{4}$ Sonke Gender Justice, Johannesburg, South Africa

Acknowledgments: This secondary analysis was conducted on data from a trial supported by the What Works to Prevent Violence? A Global Programme on Violence Against Women and Girls (VAWG) funded by the United Kingdom Government's Department for International Development (DFID). Funds for What Works were managed by the South African Medical Research Council. We also received funding from the South African Medical Research Council Social Innovation Bond, with support from the Global Fund to Fight Malaria, AIDS, and Tuberculosis. However, the views expressed do not necessarily reflect the funders' policies and the funders had no role in study design; collection, management, analysis, and interpretation of data; writing of the report; and the decision to submit the paper for publication. Dr Hatcher received additional support from National Institute of Mental Health K01 MH12118501 and Dr Weiser was supported by National Institute of Allergy and Infectious Diseases K24 AI13432603. 


\begin{abstract}
Introduction: Although poverty is often viewed as a driver of intimate partner violence (IPV), few studies have examined how changes in poverty influence men's IPV perpetration over time. One sensitive marker of poverty is food security, or the ability of households to obtain adequate nutrition. The influence of food security has been associated with IPV in cross-sectional studies, but here we examine whether a causal relationship exists.
\end{abstract}

Methods: We followed a cohort of 2,479 men living in a peri-urban settlement near Johannesburg, South Africa during the period of February 2016-August 2018. Using self-completed audio-assisted questionnaires, men responded at baseline (T0), 12 months later (T1), and 24 months later (T2). Questions about current food security, household type, childhood conditions, and past-year IPV perpetration were asked. We used cross-lagged dynamic panel modeling to assess whether food insecurity changes influenced men's IPV perpetration over time.

Results: A large proportion of men (46.9\%) reported perpetrating IPV at baseline, but this proportion reduced over time $(39.2 \%$ and $26.5 \%$ reported IPV at midline and endline, respectively). Less than half (41.4\%) of participants reported food insecurity at $\mathrm{T} 0$, and this stayed consistent at $\mathrm{T} 1$ and $\mathrm{T} 2$. In cross-sectional bivariate analysis, food insecurity was higher among those men perpetrating IPV than among those who used no violence at all three time-points. In a cross-lagged dynamic panel model, food insecurity predicted men's use of IPV one year later. Food insecurity was associated with a small, but significant, longitudinal impact on men's IPV use (standardized coefficient $=0.08, \mathrm{p}=0.035$ ) and the model fit indices were strong (RMSEA=0.027, CFI=0.993). This longitudinal association between food insecurity and IPV perpetration persisted in a final model controlling for housing status, age at baseline, and childhood exposure to abuse (coef $=0.10, p=0.022)$ that had strong fit (RMSEA=0.015, CFI=0.998). In a separate model, IPV perpetration did not predict later food security, suggesting a causal relationship from poverty to IPV perpetration.

Conclusions: Food insecurity and housing, as distinct markers of poverty, had small but persistent longitudinal effects on men's perpetration of IPV in a periurban settlement in South Africa. Addressing IPV perpetration will require examination of broader structural challenges, such as livelihoods and food security, particularly in settings with endemic poverty. Future interventions should consider livelihood strategies to improve health outcomes for both women and men.

Keywords: Intimate partner violence, food security, poverty, longitudinal analysis

Registration: ClinicalTrials.gov NCT02823288, registered on June 302016

Registered title: Multilevel Intervention for Preventing Men's Use of Violence in Urban South Africa (Sonke CHANGE Trial) 


\section{INTRODUCTION}

Intimate partner violence (IPV) is a major burden to human rights and health across the globe, with one-third of women reporting IPV victimization in their lifetime [1]. Despite considerable research to understand the predictors of women's IPV victimization, less is known about the factors associated with men's IPV perpetration. Most extant data on men's perpetration is cross-sectional, precluding the testing of direction and causality of relationships. A recent systematic review identified fewer than a dozen longitudinal studies on IPV perpetration, and all were conducted in high-resource settings [2].

Even amidst these shortcomings in the literature, limited evidence exists for a crosssectional relationship between food insecurity - a particularly sensitive marker of poverty - and IPV. When measured using a validated scale, food security scales can provide a 'snapshot' of a household situation with regards to meeting basic needs [3]. In cross-sectional research, food insecurity has been associated with increased odds of IPV victimization among women [4-6] and increased odds of men's perpetration of IPV $[7,8]$.

More broadly, poverty may be a strong underlying driver of men's IPV perpetration. North American cross-sectional research shows that men who are unemployed have higher rates of perpetrating IPV [9, 10], as do men with lower income [11]. Crosssectional research from India finds that men with fewer household assets have greater odds of perpetrating IPV $[12,13]$. Yet, other research has shown no relationship between poverty and IPV perpetration [14], or has actually suggested that men who are more better off (in contexts of high poverty) are more likely to enact violence against a partner $[15,16]$.

Only two longitudinal studies of poverty and IPV perpetration have been published to date. Krishnan and colleagues learned in India that as men's employment status became unstable over time, they had higher odds of perpetrate IPV [17]. Fox and colleagues found in the United States, however, learned that while employment 
status had no association with later IPV, financial wellbeing at baseline was strongly associated with IPV perpetration six years later [18].

One conceptual challenge to assessing cross-sectional research on poverty and IPV perpetration is that violence and poverty may have a bidirectional relationship. Evidence among women survivors shown that IPV has a negative effects on economic earning potential years after the violence occurs [19]. Less is known about IPV leading to poverty among male perpetrators, but there are several plausible explanations for a link. IPV perpetration may lead to greater household poverty if it increases financial burden for the family. This is consistent with research that demonstrates a high cost associated with the injuries, mental debilitation, and loss of work for IPV survivors [20]. Alternately, IPV perpetration could make relationships more unstable, leading to a decreased ability of the household to secure basic needs. Lastly, IPV perpetration is strongly associated with unplanned pregnancy [21], a life event that could worsen household poverty as resources are extended [22].

The current study aims to determine the longitudinal association between food insecurity and men's perpetration of IPV. Data from a randomized control trial were collected from men at three time points in a peri-urban setting in South Africa.

\section{METHODS}

\section{Data collection}

Trained research assistants recruited a volunteer sample of men during the period of February 2016 - August 2018. Eligible men lived in a pre-defined research area (called a cluster) for at least 12 months and were aged 18-40 years. The sample was recruited by a local mobilization team who used convenience sampling methods during daytime hours at local places (schools, street corners, outside restaurants) within a total of 18 clusters for a cluster randomized controlled trial. Men were followed up approximately 12 months after baseline (T1) and again at 24 months after baseline (T2). 
Research assistants asked participants at baseline (T0) to complete a locator form with contact names and numbers of the participant and close friends or family. Participants were contacted via phone call and text message at $\mathrm{T} 1$ and $\mathrm{T} 2$ and invited to complete the questionnaire at a convenient place in their neighborhood. Efforts to trace men were: multiple calls to cell phones, contacting next of kin, friends and other participants who had listed them as friends, home visits to addresses where men reported living, walks around the cluster to ask neighbors, home visits to other provinces, cities and neighborhoods within Johannesburg.

Data collection was conducted in the language of participant choice (English, isiZulu, Tswana, or Sepedi) on tablet computers using audio-computer assisted data collection (ACASI) software. ACASI allows important data to be collected about legal and illegal activity while ensuring anonymity. Data from tablets were uploaded multiple times daily to an encrypted server housed at the university.

Participation was on the basis of written, informed consent and each participant was reimbursed R50 (approximately US $\$ 3.50$ ) at T0, R100 (US \$7) at T1, and R150 (US $\$ 10.50)$ at T2. The protocol was registered with ClinicalTrials.gov (NCT02823288). Ethical approval was obtained from the University of the Witwatersrand Human Research Ethics Committee (M150443). Researchers received intensive training on IPV, the study protocol, collecting sensitive information, and ensuring data quality and participant confidentiality. Study procedures complied with ethical recommendations of the United Nations Multi-Country Study on Men and Violence.

\section{Measures}

\section{Dependent variable}

$I P V$ perpetration was measured as an index of items on physical and sexual violence towards a current or ex-partner in the past year [23]. A total of eight items asked about behaviorally specific acts of violence (e.g., hitting, strangling, forcing sex) with answers on a Likert-type scale (never, once, few, many). IPV was defined as a dichotomous measure (any use of physical or sexual violence) and as a continuous measure of intensity (summing the responses with a range of 0-40). Internal 
consistency at all timepoints was strong (Cronbach's $\boldsymbol{\alpha}=0.90,0.89,0.89$ at T0, T1 and $\mathrm{T} 2$, respectively).

\section{Time-variant variables}

Food insecurity is defined as having uncertain or limited availability of nutritionally adequate food or the inability to acquire safe, acceptable foods [24]. Beyond sheer hunger from insufficient food intake, food insecurity also includes poor dietary quality and worry or anxiety over securing food supplies [25]. Food insecurity was measured using three items of the Household Food Insecurity Access Scale that have been validated as a measure of household hunger [26]: (1) having no food in the house, (2) going to sleep hungry, and (3) going without food [26]. In addition, two items important to this highly impoverished setting were added (4) borrowing food because there was not enough, and (5) stealing food because there was not enough. Each item has a likert-type response ranging from never $(=0)$, rarely $(=1)$, sometimes $(=2)$, or often $(=3)$. Food insecurity was assessed as a continuous measure of a total scale score (range 0-15) and a 3-category index (food secure vs. moderate food insecurity vs. severe food insecurity) using validated cutoffs [26]. Internal consistency at all time points was acceptable (Cronbach's $\boldsymbol{\alpha}=0.84,0.87,0.86$ at T0, $\mathrm{T} 1$ and $\mathrm{T} 2$, respectively).

Housing was assessed using a single (non-validated) item developed during our formative research that asks about what home a person lives in. The options are ranked by order of more affluent (i.e. owning one's home or living in a governmentfunded house) to more impoverished (i.e. living in a shack behind another house, living in a single outside room). Housing was operationalized as a quasi-continuous variable (range 1-6), with a higher score indicating greater housing insecurity.

\section{Time-invariant variables}

We control for baseline age as a socio-demographic variable as men's age is strongly predictive of IPV perpetration in the literature. Men tend to "age out" of use of IPV as they get older. 
We control for baseline reports of childhood abuse since this predictor strongly influences men's adult use of IPV. Childhood abuse was measured using 15-item revised Childhood Trauma Questionnaire, a shortened version of an instrument that has been used previously in South Africa. The tool asks participants to self-report frequency of emotional, physical and sexual abuse before the age of 18 (4 items, 2 items, and 3 items, respectively), and whether they witnessed their mother being beaten by her husband or boyfriend. A higher score reflects more severe levels childhood trauma and the internal consistency was good (Cronbach's $\boldsymbol{\alpha}=0.85$ ).

\section{Analysis}

This secondary data analysis was not pre-registered. We first used descriptive statistics to describe the cohort at baseline measurement and bivariate inferential statistics to determine the cross-sectional association between IPV perpetration and our main variables of interest. The first models are cross-sectional and lagged, unadjusted logistic regressions. The purpose in estimating these models is to identify the magnitude and direction of the relationship between food insecurity and IPV perpetration, without regard to reciprocal effects [27].

We then estimated cross-lagged dynamic panel data models. Described fully elsewhere [28], cross-lagged dynamic panel data models are a relatively new analytic technique that are essentially fixed effects models estimated using a structural equation modeling (SEM) framework. Fixed effects models are useful as they eliminate the effects of all time-invariant confounders even when the potential confounders are unmeasured or undefined [27]. Fixed effects models estimate within-person changes [29], in this case determining how a person's food security level changes over time and how this impacts their IPV use.

We estimated fixed-effects models that incorporated reciprocal, lagged effects of the key variables: food insecurity and IPV perpetration [27]. Unlike traditional fixed effects, creating models within the SEM framework allows estimation of two or more 
variables that may have lagged, reciprocal effects on each other [30]. This is important since it is plausible that IPV perpetration could lead to future food insecurity. The lagged, reciprocal effects of IPV perpetration on future food insecurity are included in the SEM model by regressing food security in T2 against IPV perpetration in T0 and T1 [28].

In addition to food insecurity, we developed models with housing status, relationship status, and employment frequency. As relationship status and employment status did not demonstrate statistical significance, we removed them from the final model. In conducting fixed effects models within the SEM framework, one has the option of considering how past violence use influences later violence use. We incorporated this into the model by covarying the error terms of violence in $\mathrm{T} 1$ and $\mathrm{T} 2$. We did not, however, regress later violence on earlier intensity of violence because (counter to prevailing theory), IPV perpetration at T0 was not significantly associated with later use of IPV.

All lags were one year, as data collection occurred at baseline, 12 months, and 24 months. We use maximum likelihood with missing values (MLMV) to address missing values. Final model estimates are presented after adjusting for clustering by neighborhood. Stata16 (Statacorp, College Station, Texas) was used for all analyses.

\section{RESULTS}

The cohort was composed of 2,479 men at T0, of whom 1508 (63\%) were followed to T2, 24 months after study enrolment. Men were a median of 27 years old (range: 1840 years) at T0.

A total of 1,638 (69.4\%) men reported perpetrating one or more acts of IPV in the past year at T0. This proportion was consistent at T1, when $70.0 \%$ enacting pastyear IPV. At T2 903 men (60.0\%) reported past-year IPV.

Food insecurity was consistently reported over time. At T0, 827 (35.4\%) participants reported moderate and $703(30.1 \%)$ reported severe food insecurity. At T1 the 
proportion was similar (38.0\% and $28.0 \%$, respectively) and by T2 it had increased slightly (38.2\% and $31.7 \%$, respectively).

\section{Univariable analysis}

In univariable analysis (Figure 1), severe and moderate food insecurity was higher among those men perpetrating IPV at all three timepoints $(\chi 2=0.000,0.002$, and 0.000 for T0, T1, and T2, respectively).

Younger age and any childhood abuse were also associated with higher rates of IPV perpetration (Table 1). Being single and living in a single room or a shack were both protective of IPV perpetration.

Logistic regressions of cross-sectional and lagged associations between IPV and food insecurity suggest significant associations at some, but not all, time points (Table 2). Concurrent food security and past-year IPV perpetration were associated at T0, T1, and T2. Food security lagged by one year had an association with significantly higher odds of IPV perpetration at T1 only. Food security lagged by two years had an association with IPV at T2. IPV lagged by one year had an association with food security at T1, and lagging IPV by two years had an association with food security at T2. This suggests the importance of exploring a bidirectional relationship between food and IPV perpetration.

\section{Cross-lagged dynamic panel model}

We present two cross-lagged dynamic panel models (Table 3) that lag food insecurity by one year and model the effects on later IPV perpetration. In Model 1, only food insecurity is considered and changes in food are associated with a small but significant increase in IPV perpetration one year later. Every standardized increase in food insecurity is associated with a 0.09 standard deviation increase in IPV intensity. Model fit indices are acceptable (RMSEA=0.047, CFI=0.990). 
In Model 2, we add time invariant socio-demographics (age and childhood abuse exposure) and time variant predictors (housing status and past IPV perpetration). In this model, food insecurity retains its consistent association with later IPV perpetration. Food insecurity is independently associated with a small but significant increase in men's IPV perpetration (standardized coefficient (coef)=0.09, $p=0.032$ ) even after controlling for other covariates known to influence IPV perpetration (Figure 2). Housing status is associated with later IPV (coef $=0.08$, $p=0.089)$ as is age at baseline (coef $=-0.09, p=0.001)$ and childhood abuse exposure (coef $=0.24, p=0.000)$. Importantly, this model does account for potential bidirectionality: adjusting for IPV perpetration's later impact on food security. Fit indices are acceptable (RMSEA=0.031, CFI=0.984).

In Table 4, we examine bidirectionality of poverty and men's IPV perpetration more closely. This cross-lagged dynamic panel model aims to assess lagged IPV use as a predictor of later food insecurity, while controlling for housing, age at baseline, and childhood abuse. In this model, men's IPV perpetration is not a driver of later food security $(p=0.276)$. On the other hand, age at baseline and childhood abuse do predict adult food insecurity ( $p=0.000$ and $p=0.000$, respectively). Model fit was poor (RMSEA=0.080, TLI=0.661), suggesting that a reverse causal hypothesis of IPV perpetration leading to later food insecurity do not fit these data.

\section{DISCUSSION}

In this study, we found that changes in food insecurity had significant impact on men's perpetration of IPV over time. In a cohort of 2,479 men from South Africa followed at three timepoints, a majority (69.4\%) reported recent use of IPV and were food insecure (65.5\%). The longitudinal effect of food security on IPV perpetration was consistent even when controlling for other important markers of socio-economic status, such as changes in housing status, and time-invariant controls of age and childhood exposure to abuse. These data suggest that shifts in household food insecurity may be a modifiable risk factor for reducing men's IPV perpetration.

The use of cross-lagged dynamic panel data modeling was a strength of this study. 
Estimating fixed effects models for panel data in the SEM framework allow for stronger causal inferences from non-experimental data compared to other analytical techniques [30]. Longitudinal data is particularly important for the poverty and IPV fields since, to our knowledge, no extant literature exists around men's perpetration of IPV and markers of poverty.

It is plausible that other structural or historical factors drive both food insecurity and men's use of IPV. We attempted account for this by including fixed effects in the model, which control for within-person, unmeasured covariates. Another important innovation was examining how food insecurity impacts later violence, and its corollary: how IPV perpetration impacts later food security. We found no evidence of the latter association, suggesting that with these data and relatively short lag times of one year, men's violence does not drive later food insecurity.

Childhood abuse, as a measured, time-invariant covariate, did play a role in both food insecurity and IPV perpetration. Child abuse is well-recognized as a major longitudinal driver of men's later violence in adulthood [31-33]. In addition to physical or sexual abuse and neglect, childhood poverty is a longitudinal predictor of adult IPV perpetration in high-resourced setting studies [34-36]. Our findings of the role that childhood abuse plays in men's IPV perpetration and adult food security confirm that violence victimization, particularly in childhood, informs later health and economic outcomes.

Theoretical work around poverty and health, in addition to a small number of empirical studies, may help explain the rationale behind food insecurity's ties to IPV perpetration. Goode's resource theory of family violence posits that men with limited financial resources may try to reassert power in the household through the use of physical force [37]. While resource theory has found support in some cross-sectional data $[38,39]$ others have failed to support this theoretical approach with empirical data $[18,40]$. These data may provide the first longitudinal evidence consistent with resource theory, showing that men whose food insecurity increases over time have higher odds of IPV perpetration. 
However, on its own, resource theory fails to account for the important gendered dynamics of IPV perpetration. Masculinities research has long posited that men attain dominance through socially sanctioned means, such as earning income, being a provider, or serving as a patriarch within the household [41], and that this dominance is consolidated through the use of violence. Relative resource theory highlights that threats to the male role as a breadwinner may be more important than changes in income on their own $[42,43]$. In the U.S., men's controlling behavior increased when the masculine "breadwinner" role is threatened [44]. In Cote d'Ivoire, the stress of food insecurity led to IPV perpetration among men when men felt unable to meet their gendered role of providing for the family [45].

Stress theory suggests that a lack of material resources may lead to violence as stress depletes psychological resources required to enact self-control over the violence act $[18,46]$. Stress theory has been supported in empirical studies from both low and high-income settings $[18,38,47,48]$. In a broader "mental health" lens that extends beyond only stress, we previously found food insecurity was related to greater depression symptoms, which in turn was associated with higher odds of IPV perpetration [8].

\section{Implications for program and policy}

These findings suggest that food security and livelihood programs with men may reduce partner violence perpetration. Increasing access to food, through nutrition support, could attenuate men's IPV perpetration. One Mauritian study suggests that supplementing child nutrition can measurably reduce a father's IPV perpetration [49]. No studies, to our knowledge, have yet examined other forms of household nutritional support and men's IPV perpetration.

Cash transfer programs with women have shown that offering families a cash grant can reduce women's IPV victimization [50-52], yet in a setting like South Africa where a large proportion of the population already depend on cash grants, it is unclear how additional transfers would alter rates of violence. Little research has explored food insecurity or economic interventions among men, but pilot studies 
suggest they may reduce IPV perpetration [53, 54]. Despite potential downsides if economic interventions reinforce traditional male roles, concerns that an influx of cash might actually increase violence perpetration (by, for example, increasing alcohol intake) have not been borne out in the literature [55].

One advance in development economics is the increased focus on assets and savings, rather than loans and credits. Increasing a family's assets (through savings or individual development accounts, for example) seems to have a marked decrease in family stress [56]. While savings approaches have begun to be tested among female survivors [57, 58], our results suggest that they may be valuable for men. If coupled with gender transformative training, such savings and asset building programming could have health outcomes related to IPV perpetration.

\section{Limitations}

Our data is drawn from a convenience sample of men recruited for a cluster randomized controlled trial, precluding the ability to generalize findings to the entire peri-urban settlement or other settings. Self-report of men's violence use is problematic but is currently the state of the science for IPV research. The anonymity of ACASI may assist with accurate reporting of IPV by men by limiting social desirability bias. Dynamic panel modeling is a within-person analysis approach that predicts how changes in one man's food security status may relate to his perpetration of IPV over time. It does not, however, provide information about population-level considerations. One important assumption in fixed effects models is that the unmeasured confounders (denoted by $\alpha$ ) are accounted for so long as they stable over time [59]. For example, study arm (intervention vs. control) is stable over time and is thus incorporated in the $\alpha$ estimate. However, it is possible that unmeasured time-variant confounders, such as crime experienced in daily life, do change over time. We cannot rule out bidirectionality, since it is possible that longer lags would have shown that changes in men's IPV perpetration over time does influence their later food security status. However, within a two-year timeframe, we can conclude the model fit for food insecurity driving later violence is much stronger. 


\section{Conclusion}

We found that food insecurity is longitudinally associated with IPV perpetration among men. While men who were food secure drastically reduced their use of IPV over time, those with food insecurity stayed relatively more consistent in their IPV perpetration. These findings can inform future violence prevention efforts, particularly in settings with high rates of endemic poverty. While a bidirectional relationship is plausible, our findings suggest that food insecurity seems to drive later violence rather than visa versa. In order to protect the health and wellbeing of women and men, urgent response to the intersecting issues of poverty and IPV are needed. 
References

1. Devries KM, Mak JY, Garcia-Moreno C, Petzold M, Child JC, Falder G, et al. The global prevalence of intimate partner violence against women. Science. 2013;340(6140):1527-8. Epub 2013/06/22. doi: 10.1126/science. 1240937 science.1240937 [pii]. PubMed PMID: 23788730.

2. Costa BM, Kaestle CE, Walker A, Curtis A, Day A, Toumbourou JW, et al. Longitudinal predictors of domestic violence perpetration and victimization: A systematic review. Aggression and violent behavior. 2015;24:261-72.

3. Coudouel A, Hentschel JS, Wodon QT. Poverty measurement and analysis. A Sourcebook for poverty reduction strategies. 2002;1:27-74.

4. Breiding MJ, Basile KC, Klevens J, Smith SG. Economic Insecurity and Intimate Partner and Sexual Violence Victimization. Am J Prev Med. 2017;53(4):457-64. doi: 10.1016/j.amepre.2017.03.021. PubMed PMID: 28501239.

5. Melchior H, Hergert A, Hofreuter-Gatgens K, Bergelt C, Morfeld M, Schulz H, et al. [Predictors of treatment duration for inpatients with mental disorders--a systematic literature review]. Z Psychosom Med Psychother. 2010;56(4):399-418. doi: 10.13109/zptm.2010.56.4.399. PubMed PMID: 21243609.

6. Ricks JL, Cochran SD, Arah OA, Williams JK, Seeman TE. Food insecurity and intimate partner violence against women: results from the California Women's Health Survey. Public Health Nutr. 2016;19(5):914-23. doi: 10.1017/S1368980015001986. PubMed PMID: 26096652. 7. Fulu E, Jewkes R, Roselli T, Garcia-Moreno C, Men UNM-cC-sSo, Violence research t. Prevalence of and factors associated with male perpetration of intimate partner violence: findings from the UN Multi-country Cross-sectional Study on Men and Violence in Asia and the Pacific. Lancet Glob Health. 2013;1(4):e187-207. doi: 10.1016/S2214-109X(13)70074-3. PubMed PMID: 25104345.

8. Authors. 2019.

9. Brownridge DA, Halli SS. Double jeopardy?: Violence against immigrant women in Canada. Violence and victims. 2002;17(4):455.

10. Caetano R, Vaeth PA, Ramisetty-Mikler S. Intimate partner violence victim and perpetrator characteristics among couples in the United States. Journal of Family Violence. 2008;23(6):507-18.

11. Pan HS, Neidig PH, O'leary KD. Predicting mild and severe husband-to-wife physical aggression. Journal of consulting and clinical Psychology. 1994;62(5):975.

12. Koenig MA, Stephenson R, Ahmed S, Jejeebhoy SJ, Campbell J. Individual and contextual determinants of domestic violence in North India. American journal of public health. 2006;96(1):132-8.

13. Martin SL, Moracco KE, Garro J, Tsui AO, Kupper LL, Chase JL, et al. Domestic violence across generations: findings from northern India. International journal of epidemiology. 2002;31(3):560-72.

14. Fleming PJ, McCleary-Sills J, Morton M, Levtov R, Heilman B, Barker G. Risk factors for men's lifetime perpetration of physical violence against intimate partners: results from the international men and gender equality survey (IMAGES) in eight countries. PloS one. 2015;10(3): 0118639 .

15. Jewkes R, Dunkle K, Koss MP, Levin JB, Nduna M, Jama N, et al. Rape perpetration by young, rural South African men: Prevalence, patterns and risk factors. Soc Sci Med. 2006;63:2949-61.

16. Decker MR, Peitzmeier S, Olumide A, Acharya R, Ojengbede O, Covarrubias L, et al. Prevalence and health impact of intimate partner violence and non-partner sexual violence among female adolescents aged 15-19 years in vulnerable urban environments: a multi-country study. Journal of Adolescent Health. 2014;55(6):S58-S67. 
17. Krishnan S, Rocca CH, Hubbard AE, Subbiah K, Edmeades J, Padian NS. Do changes in spousal employment status lead to domestic violence? Insights from a prospective study in Bangalore, India. Soc Sci Med. 2010;70(1):136-43. Epub 2009/10/16. doi: S02779536(09)00617-0 [pii] 10.1016/j.socscimed.2009.09.026. PubMed PMID: 19828220.

18. Fox GL, Benson ML, DeMaris AA, Wyk J. Economic distress and intimate violence: Testing family stress and resources theories. Journal of Marriage and Family. 2002;64(3):793807.

19. Lindhorst T, Oxford M, Gillmore MR. Longitudinal effects of domestic violence on employment and welfare outcomes. Journal of interpersonal violence. 2007;22(7):812-28.

20. Peterson C, Kearns MC, McIntosh WL, Estefan LF, Nicolaidis C, McCollister KE, et al. Lifetime Economic Burden of Intimate Partner Violence Among U.S. Adults. Am J Prev Med. 2018;55(4):433-44. doi: 10.1016/j.amepre.2018.04.049. PubMed PMID: 30166082; PubMed Central PMCID: PMCPMC6161830.

21. Coker AL. Does physical intimate partner violence affect sexual health? A systematic review. Trauma Violence Abuse. 2007;8(2):149-77. doi: 10.1177/1524838007301162. PubMed PMID: 17545572.

22. Gibbs A, Duvvury N, Scriver S. What Works Evidence Review: The relationship between poverty and intimate partner violence. Pretoria: South African Medical Research Council, 2017.

23. Jewkes R, Sikweyiya Y, Morrell R, Dunkle K. The relationship between intimate partner violence, rape and HIV amongst South African men: a cross-sectional study. PLoS One. 2011;6(9):e24256. Epub 2011/09/22. doi: 10.1371/journal.pone.0024256 PONE-D-11-04522 [pii]. PubMed PMID: 21935392.

24. Radimer KL, Olson CM, Greene JC, Campbell CC, Habicht JP. Understanding hunger and developing indicators to assess it in women and children. Journal of Nutrition Education. 1992;24(1 suppl.):36S-44S.

25. Bickel G, Nord M, Price C, Hamilton W, Cook J. Guide to Measuring Household Food Security, Revised 2000. Alexandria, VA: U.S. Department of Agriculture, Food and Nutrition Service, 2000 March, 2000. Report No.

26. Deitchler M, Ballard T, Swindale A, Coates J. Validation of a measure of household hunger for cross-cultural use. Washington, DC: Food and Nurtrition Technical Assistance II Project (FANTA-2), Acedemy for Educational Development. 2010.

27. Levanon A, England P, Allison P. Occupational feminization and pay: Assessing causal dynamics using 1950-2000 US census data. Social Forces. 2009;88(2):865-91.

28. Allison PD, Williams R, Moral-Benito E. Maximum likelihood for cross-lagged panel models with fixed effects. Socius. 2017;3:2378023117710578.

29. Boman J, Mowen TJ. The role of turning points in establishing baseline differences between people in developmental and life - course criminology. Criminology. 2018;56(1):191224.

30. Allison PD. Fixed effects regression models: SAGE publications; 2009.

31. Hébert M, Daspe M-È, Lapierre A, Godbout N, Blais M, Fernet M, et al. A meta-analysis of risk and protective factors for dating violence victimization: The role of family and peer interpersonal context. Trauma, Violence, \& Abuse. 2017:1524838017725336.

32. Roberts AL, McLaughlin KA, Conron KJ, Koenen KC. Adulthood stressors, history of childhood adversity, and risk of perpetration of intimate partner violence. American journal of preventive medicine. 2011;40(2):128-38.

33. Jewkes R, Fulu E, Roselli T, Garcia-Moreno C. Prevalence of and factors associated with non-partner rape perpetration: findings from the UN Multi-country Cross-sectional Study on Men and Violence in Asia and the Pacific. The Lancet Global Health. 2013;1(4):e208-e18. 
34. Fergusson DM, Boden JM, Horwood LJ. Developmental antecedents of interpartner violence in a New Zealand birth cohort. Journal of Family Violence. 2008;23(8):737-53.

35. Magdol L, Moffitt TE, Caspi A, Silva PA. Developmental antecedents of partner abuse: a prospective-longitudinal study. Journal of abnormal psychology. 1998;107(3):375.

36. Cunradi CB, Caetano R, Schafer J. Socioeconomic predictors of intimate partner violence among White, Black, and Hispanic couples in the United States. Journal of family violence. 2002;17(4):377-89.

37. Goode WJ. Force and violence in the family. Journal of Marriage and the Family. 1971:624-36.

38. VanderEnde KE, Sibley LM, Cheong YF, Naved RT, Yount KM. Community economic status and intimate partner violence against women in bangladesh: compositional or contextual effects? Violence Against Women. 2015;21(6):679-99. doi: 10.1177/1077801215576938. PubMed PMID: 25845617.

39. Schneider D, Harknett K, McLanahan S. Intimate partner violence in the Great Recession. Demography. 2016;53(2):471-505.

40. Yount KM, Higgins EM, VanderEnde KE, Krause KH, Minh TH, Schuler SR, et al. Men's perpetration of intimate partner violence in Vietnam: Gendered social learning and the challenges of masculinity. Men and Masculinities. 2016;19(1):64-84.

41. Connell RW, Messerschmidt JW. Hegemonic masculinity - Rethinking the concept. Gender \& Society. 2005;19(6):829-59. doi: 10.1177/0891243205278639. PubMed PMID: ISI:000233168600007.

42. Anderson KL. Gender, status, and domestic violence: An integration of feminist and family violence approaches. Journal of Marriage and the Family. 1997:655-69.

43. Atkinson MP, Greenstein TN, Lang MM. For women, breadwinning can be dangerous: Gendered resource theory and wife abuse. Journal of Marriage and Family. 2005;67(5):1137-48. 44. Melzer SA. Gender, work, and intimate violence: Men's occupational violence spillover and compensatory violence. Journal of Marriage and Family. 2002;64(4):820-32.

45. Cardoso LF, Gupta J, Shuman S, Cole H, Kpebo D, Falb KL. What Factors Contribute to Intimate Partner Violence Against Women in Urban, Conflict-Affected Settings? Qualitative Findings from Abidjan, Cote d'Ivoire. J Urban Health. 2016;93(2):364-78. doi: 10.1007/s11524016-0029-x. PubMed PMID: 27000124; PubMed Central PMCID: PMCPMC4835354.

46. Baumeister RF, Heatherton TF, Tice DM. Losing control: How and why people fail at self-regulation: Academic press; 1994.

47. Lucero JL, Lim S, Santiago AM. Changes in economic hardship and intimate partner violence: A family stress framework. Journal of family and economic issues. 2016;37(3):395-406. 48. Buller AM, Hidrobo M, Peterman A, Heise L. The way to a man's heart is through his stomach?: a mixed methods study on causal mechanisms through which cash and in-kind food transfers decreased intimate partner violence. BMC Public Health. 2016;16:488. doi: 10.1186/s12889-016-3129-3. PubMed PMID: 27278935; PubMed Central PMCID: PMCPMC4898371.

49. Portnoy J, Raine A, Liu J, Hibbeln JR. Reductions of intimate partner violence resulting from supplementing children with omega-3 fatty acids: a randomized, double-blind, placebocontrolled, stratified, parallel-group trial. Aggressive Behavior. 2018;44(5):491-500. PubMed PMID: 20193042786. Publication Type: Journal Article. Language: English. Number of References: many ref. Subject Subsets: Rural Development.

50. Bobonis GJ, González-Brenes M, Castro R. Public transfers and domestic violence: The roles of private information and spousal control. American Economic Journal: Economic Policy. 2013;5(1):179-205.

51. Hidrobo M, Peterman A, Heise L. The effect of cash, vouchers, and food transfers on intimate partner violence: evidence from a randomized experiment in Northern Ecuador.

American Economic Journal: Applied Economics. 2016;8(3):284-303. 
52. Haushofer J, Shapiro J. The short-term impact of unconditional cash transfers to the poor: Experimental evidence from Kenya. The Quarterly Journal of Economics. 2016;131(4):19732042.

53. Jewkes R, Gibbs A, Jama-Shai N, Willan S, Misselhorn A, Mushinga M, et al. Stepping Stones and Creating Futures intervention: shortened interrupted time series evaluation of a behavioural and structural health promotion and violence prevention intervention for young people in informal settlements in Durban, South Africa. BMC public health. 2014;14(1):1325.

54. Heath R, Hidrobo M, Roy S. Cash transfers, polygamy, and intimate partner violence: Experimental evidence from Mali. Washington, DC: International Food Policy Research Institute (IFPRI), 2018.

55. Handa S, Daidone S, Peterman A, Davis B, Pereira A, Palermo T, et al. Myth-busting? Confronting Six Common Perceptions about Unconditional Cash Transfers as a Poverty Reduction Strategy in Africa. 2017.

56. Rothwell DW, Han CK. Exploring the relationship between assets and family stress among low - income families. Family Relations. 2010;59(4):396-407.

57. Sanders CK. Savings for survivors: an individual development account program for survivors of intimate-partner violence. Journal of Social Service Research. 2014;40(3):297-312. 58. Hahn SA, Postmus JL. Economic empowerment of impoverished IPV survivors: A review of best practice literature and implications for policy. Trauma, Violence, \& Abuse. 2014;15(2):79-93.

59. Firebaugh G, Warner C, Massoglia M. Fixed effects, random effects, and hybrid models for causal analysis. Handbook of causal analysis for social research: Springer; 2013. p. 113-32. 
Table 1: Descriptive statistics and bivariate association between covariates and use of recent intimate partner violence at baseline $(n=2,479)$

Total cohort

IPV Perpetration at To

$\begin{array}{cccc} & \text { No IPV } & \text { Recent IPV } & \begin{array}{c}\mathrm{p} \text { value } \\ (\chi 2 \text {, wilcoxon, } \\ \text { or t-test })\end{array}\end{array}$

Dependent variable

IPV perpetration $\quad 1638(69.4 \%)$

Time variant variables

Food insecurity

$1530(65.5 \%) \quad 50.1 \% \quad 72.9 \% \quad 0.000$

Relationship status:

$391(16.4 \%)$

$23.9 \% \quad 13.0 \%$

0.000

single

Lives in shack or single

$1466(62.0 \%)$

$66.5 \% \quad 59.8 \%$

0.002

room

Time invariant variables

Age at To

$27(23-32)$

28.4

27.1

0.000

Any childhood abuse

$1962(82.2 \%)$

$61.8 \%$

$91.7 \%$

0.000

IQR: inter-quartile range; IPV: intimate partner violence

All time variant variables and the dependent variables are presented as at baseline 


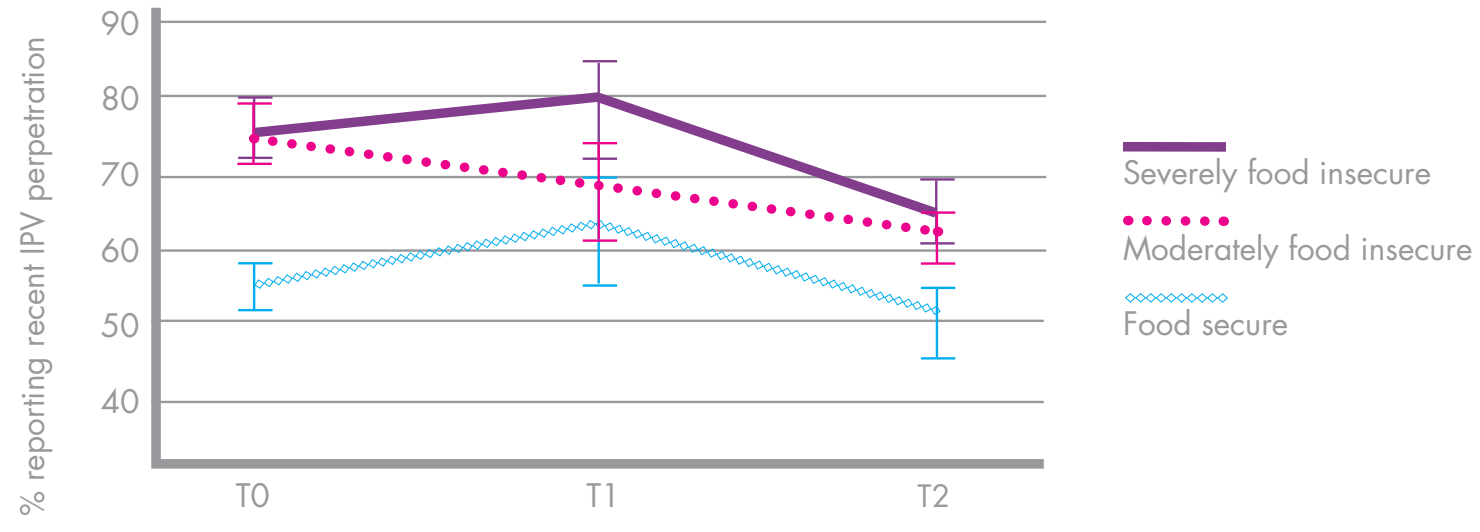

Fig 1. Men's intimate partner violence perpetration by food security status $(n=2$ 479) 
Table 2: Association between food insecurity and men's IPV perpetration from unadjusted logistic regression models

\begin{tabular}{lccc} 
& \multicolumn{3}{c}{ Any IPV perpetration } \\
& To & T1 & T2 \\
& OR & OR & OR \\
\cline { 2 - 4 } Food secure To & $\mathbf{0 . 3 7 ^ { * * * }}$ & $\mathbf{0 . 6 4 ^ { * }}$ & $\mathbf{0 . 7 4 ^ { * * }}$ \\
Food secure T1 & $0.70^{\circ}$ & $\mathbf{0 . 6 2 ^ { * }}$ & 0.75 \\
Food secure T2 & $\mathbf{0 . 7 8 ^ { * }}$ & $\mathbf{0 . 6 2 ^ { * }}$ & $\mathbf{0 . 5 8 ^ { * * * }}$ \\
& & & \\
\hline
\end{tabular}

${ }^{\circ} p<0.08,{ }^{*} p<0.05,{ }^{* *} p<0.01,{ }^{* * *} p<0.001$ 
Table 3: Cross-lagged dynamic panel models examining IPV perpetration $(n=2,479)$

\begin{tabular}{|c|c|c|c|c|}
\hline \multicolumn{3}{|c|}{ Model 1} & \multicolumn{2}{|c|}{ Model 2} \\
\hline Coef & SE & $\mathrm{p}$ value & Coef & SE \\
\hline
\end{tabular}

\section{Time variant variables}

Food insecurity

$$
0.090 .04
$$

0.040

0.09

$0.04 \quad 0.034$

Housing status

0.08

$0.05 \quad 0.089$

Time invariant variables

Age at baseline

$-\quad-$

$-0.09$

0.02

0.001

Childhood abuse

- -

0.24

0.03

0.000

Alpha

0.70

0.05

0.000

0.65

0.05

0.000

Fit indices

$\begin{array}{lcc}\text { Chi2 p-value } & 0.010 & 0.009 \\ \text { Degrees of freedom } & 1 & 4 \\ \text { RMSEA } & 0.047 & 0.031 \\ \text { CFI } & 0.990 & 0.984\end{array}$

Coef: standardized coefficient; SE:standard error; IPV: intimate partner violence; RMSEA: root mean squared estimate of approximation; CFI: conditional fit index

Models account for past use of violence and bidirectional nature of association (i.e. IPV perpetration leading to later food insecurity) 
Table 4: Bidirectional cross-lagged dynamic panel model of food insecurity $(n=2,478)$

\begin{tabular}{lccc} 
& Coef & SE & $\begin{array}{c}\text { p } \\
\text { value }\end{array}$ \\
\cline { 2 - 4 } $\begin{array}{l}\text { Time variant variables } \\
\text { IPV perpetration }\end{array}$ & 0.02 & 0.02 & 0.276 \\
Housing status & 0.01 & 0.13 & 0.962 \\
Time invariant variables & & & \\
Age at baseline & 0.05 & 0.01 & 0.000 \\
Childhood abuse & 0.05 & 0.01 & 0.000 \\
Alpha & 2.00 & 22.20 & 0.928 \\
Fit indices & & & \\
$\begin{array}{l}\text { Chi2 p-value } \\
\text { Degrees of freedom }\end{array}$ & 0.00 & & \\
RMSEA & 4 & & \\
TLI & 0.080 & & \\
\hline Coef: standardized coefficient; SE:standard error; IPV: \\
intimate partner violence; RMSEA: root mean squared \\
estimate of approximation; CFI: conditional fit index
\end{tabular}

